\title{
HIGH TEMPERATURE CORROSION BEHAVIOUR OF NICR-BASED COATINGS APPLIED BY TWIN WIRE ARC SPRAY TECHNOLOGY
}

\author{
${ }^{1}$ Kateřina LENCOVÁ, ${ }^{2}$ Marek VOSTŘÁK, ${ }^{3}$ Jana NAĎOVÁ, ${ }^{4}$ František LUKÁČ, ${ }^{5}$ Radek MUŠÁLEK \\ Research and Testing Institute Pilsen, Plzeň, Czech Republic, EU, \\ 1'lencova@vzuplzen.cz, ${ }^{2}$ vostrak@vzuplzen.cz, ${ }^{3}$ nadova@vzuplzen.cz \\ Institute of Plasma Physics of CAS, Praha, EU, \\ 4musalek@ipp.cas.cz,5lukac@ipp.cas.cz
}

https://doi.org/10.37904/metal.2021.4185

\begin{abstract}
High temperature corrosion is a serious problem related to the combustion of heavy oils with high vanadium contents. Protective overlay coatings are used to allow functioning of engineering components under extreme conditions and provide corrosion resistance to extend the component life. This article is concerned with the high temperature corrosion behaviour of two protective $\mathrm{NiCr}$-based coatings and bare structural steel 1.4959 (W.nr.) in a molten salt environment of $40 \% \mathrm{Na}_{2} \mathrm{SO}_{4}$ and $60 \% \mathrm{~V}_{2} \mathrm{O}_{5}$ at $750{ }^{\circ} \mathrm{C}$ under cyclic condition. $\mathrm{NiCr}$ and NiCrMoNbTa coating was deposited on steel 1.4903 (W.nr.) by Twin wire arc spray technology (TWAS). To establish the kinetics of corrosion, the thermogravimetric technique was used. The X-ray diffraction (XRD), scanning electron microscope (SEM) and energy dispersive spectroscopy (EDS) techniques were used to analyse the corrosion products and determine the corrosion mechanism. The hot corrosion resistance of both coatings was better than bare steel samples. The NiCrMoNbTa coating showed better corrosion behaviour than the NiCr coating. However, also the NiCr coating provides sufficient protection to the substrate material.
\end{abstract}

Keywords: High temperature corrosion, Twin Wire Arc Spray, NiCr-based coating, NiCr, NiCrMoNbTa, Heavy oils, Vanadium

\section{INTRODUCTION}

High-temperature corrosion is a serious problem in the case of the materials degradation of boilers, gas turbines, internal combustion engines and industrial waste incinerators. However, superalloys are designed for high-temperature applications, they are not able to meet a sufficiently hot corrosion resistance and high thermal strength at the same time. For this reason, protective coatings are applied to the materials of hightemperature equipment, which prolong their service life. [1,2,3].

\section{COATINGS DEPOSITION AND MOLTEN SALT CORROSION TEST}

Cyclic high temperature corrosion test was performed on Twin Wire Arc Spray applied NiCr-based coatings as well as uncoated steels samples. $\mathrm{NiCr}$ and $\mathrm{NiCrMoNbTa}$ coatings were deposited on high temperature corrosion resistant chrome-molybdenum steel 1.4903 (W.nr.). Uncoated nickel-iron-chromium steel 1.4959 (W.nr.) and chrome-molybdenum steel 1.4903 were included in the high temperature corrosion test for comparison. The specimens were exposed to the molten salt environment $40 \% \mathrm{Na}_{2} \mathrm{SO}_{4}$ and $60 \% \mathrm{~V}_{2} \mathrm{O}_{5}$ at $750{ }^{\circ} \mathrm{C}$ under cyclic condition, simulating the real working environment of energy systems burning oil-based fuels. Each cycle comprised of $1 \mathrm{~h}$ of heating at $750^{\circ} \mathrm{C}$ in a silicon carbide furnace followed by 20 min cooling at room temperature. In total, 50 cycles were applied. For the test, samples of size $20 \times 20 \times 5 \mathrm{~mm}$ were used. The specimens were placed in crucible boats. The weight gain of the tested samples wasn't affected by possible peeling of the scale, because all parts of the scale were captured in the crucible and were weighted 
with the samples. The resistance of the tested specimens to the high temperature corrosion was evaluated using the thermogravimetric method to determine the kinetics of corrosion products. X-ray diffraction (XRD), scanning electron microscope (SEM) and energy dispersive spectroscopy (EDS) techniques were used to analyse the corrosion products and determine the corrosion mechanism [4].

\section{RESULTS}

\subsection{Corrosion kinetic}

Weight change measurements were performed after each testing cycle to establish the kinetics of corrosion. The weight gain graph for coatings and bare steel substrate during cyclic exposure to the molten salt environment is shown in (Figure 1). The first 10 testing cycles of the high temperature corrosion test are not recorded in the weight gain graph because the corrosion behaviour of the samples was affected by the formation of the passivation oxide layer and the test stabilization. Weight gains observed during the high temperature corrosion test were caused by the formation of corrosion products. The best corrosion resistance was shown by the sample with the smallest oxidation rate. The gravimetric curves shapes of both coatings and steel 1.4903 are comparable. Both coatings show much lover weight gains than the bare steel specimens. $\mathrm{NiCrMoNbTa}$ coating shown better corrosion behaviour than $\mathrm{NiCr}$ coating. The gravimetric curve of steel 1.4959 has an almost linear course. From this, it can be concluded that no protective passivation oxide layer was formed on the coating surface, which would slow the progression of corrosion.

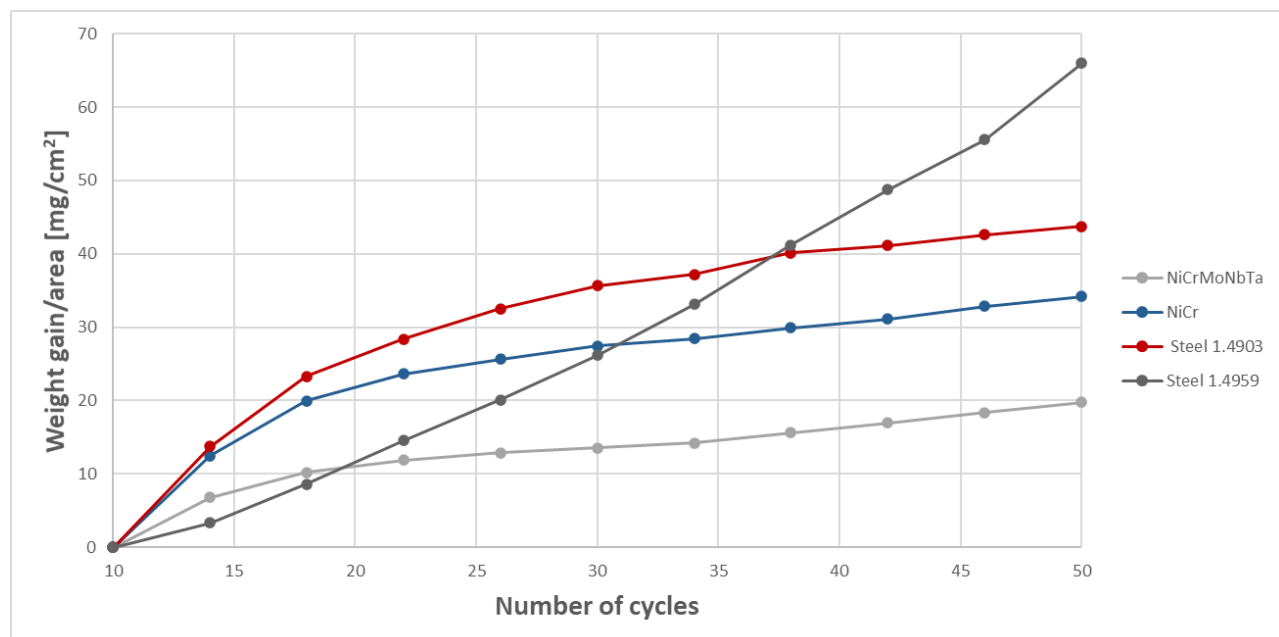

Figure 1 Weight gain versus the number of test cycles graph for tested samples after the exposure to the $40 \% \mathrm{Na}_{2} \mathrm{SO}_{4}$ and $60 \% \mathrm{~V}_{2} \mathrm{O}_{5}$ corrosion environment

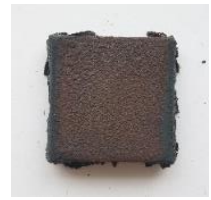

a) $\mathrm{NiCr}$

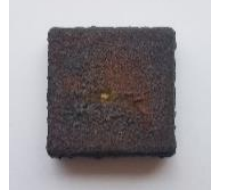

b) $\mathrm{NiCrMoNbTa}$

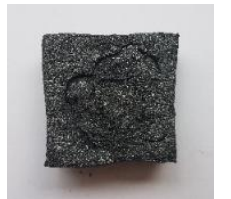

c) Steel 1.4903

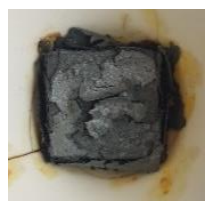

d) Steel1.4959

Figure 2 Macroscopic photography of tested samples after exposure to $40 \% \mathrm{Na}_{2} \mathrm{SO}_{4}$ and $60 \% \mathrm{~V}_{2} \mathrm{O}_{5}$ corrosion environment

Macroscopic photography of both coating after exposure are given in (Figures $\mathbf{2}$ a and $\mathbf{2}$ b). Loss of original shape was observed for the steel 1.4903 sample (Figure $2 \mathbf{c}$ ). The uncoated 1.4959 steel showed significant weight gain and extensive peeling (Figure $\mathbf{2} \mathbf{d}$ ) during the entire period of the test. 


\subsection{SEM and EDS cross-section analysis}

SEM and EDS techniques were used to analyse the corrosion products and determine the corrosion mechanism. The results of SEM and EDS cross section analyses of coatings and bare specimens after the exposure to the aggressive corrosion environment $40 \% \mathrm{Na}_{2} \mathrm{SO}_{4}$ and $60 \% \mathrm{~V}_{2} \mathrm{O}_{5}$ are given in (Figures 3-7).

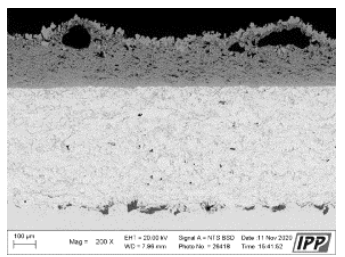

a) $\mathrm{NiCr}$

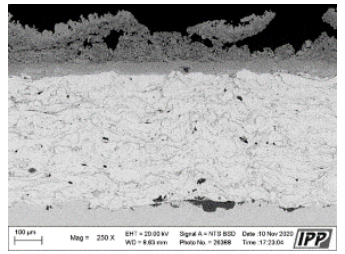

b) NiCrMoNbTa

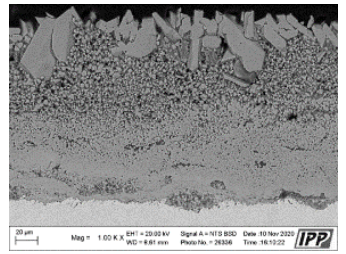

C) Steel 1.4903

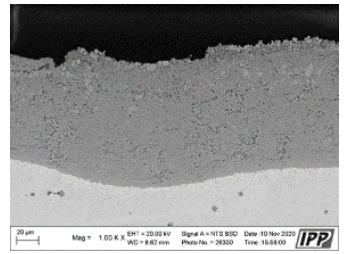

d) Steel 1.4959

Figure 3 SEM photograph of tested samples after exposure to the $40 \% \mathrm{Na}_{2} \mathrm{SO}_{4}$ a $60 \% \mathrm{~V}_{2} \mathrm{O}_{5}$ corrosion environment

A continual and porous corrosion layer was formed on the surface of the $\mathrm{NiCr}$ sample (Figure 3). Hightemperature corrosion attack of the coating has a surface character. The corrosion layer is formed by oxides of nickel, chromium and vanadium, which comes from a corrosive environment. Sulphur from the corrosive environment diffused through the corrosion layer into the coating.
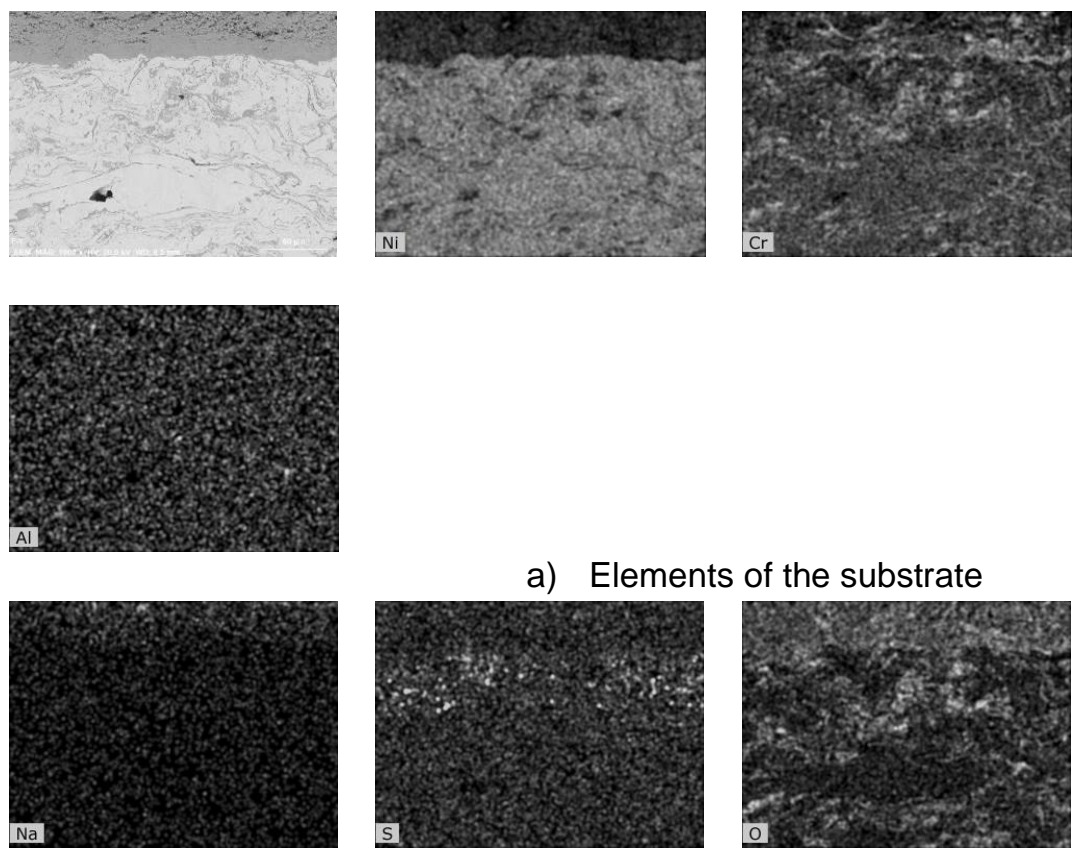

b) Corrosion elements

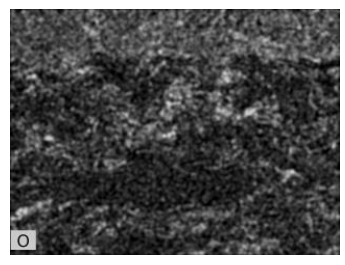

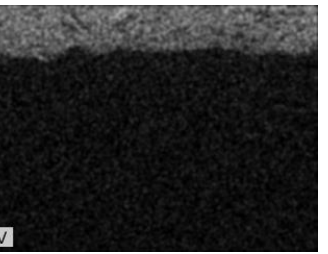
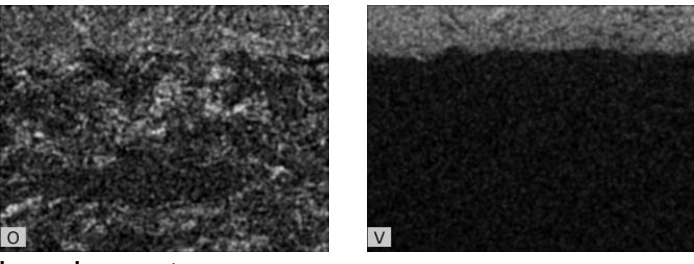

Figure 4 SEM photograph and EDS map of the cross-section of NiCr coating after the exposure to the $40 \% \mathrm{Na}_{2} \mathrm{SO}_{4}$ a $60 \% \mathrm{~V}_{2} \mathrm{O}_{5}$ corrosion environment a) Elements of the substrate b) Corrosion elements

The corrosion layer on the top of NiCrMoNbTa coating (Figure 5) is mainly formed by oxides of chromium and vanadium. Small amounts of nickel, niobium and tantalum were also detected. In the case of molybdenum and sulphur, the peaks in the EDS spectrum overlap, so they could not be distinguished. High temperature corrosion attack of the coating has a surface character. 

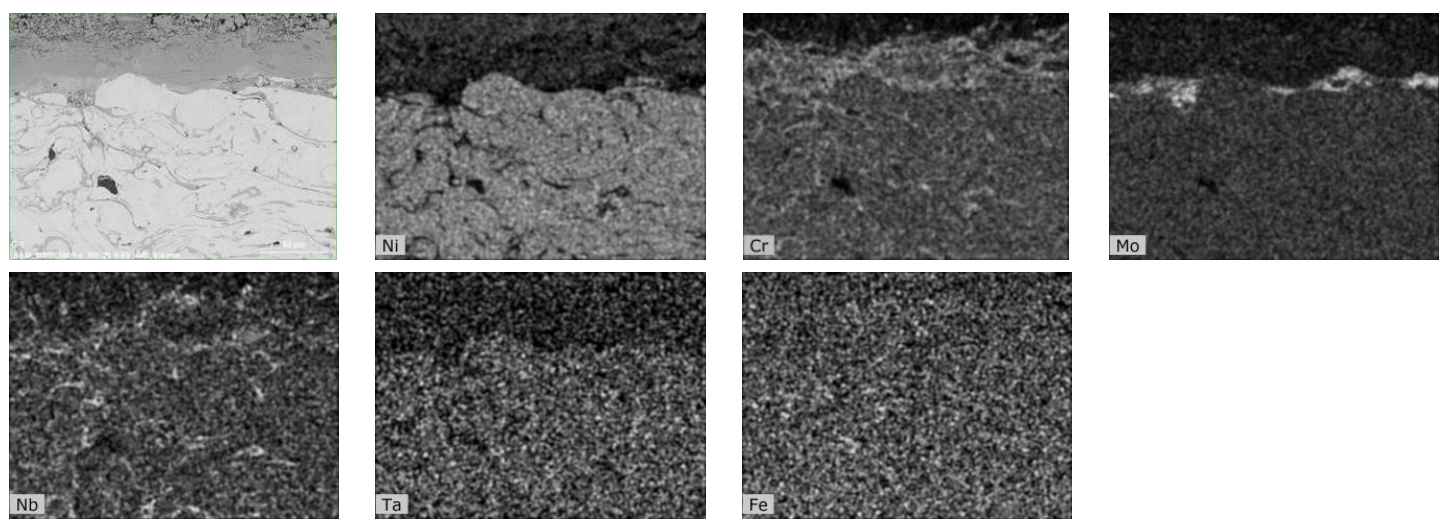

a) Coating elements
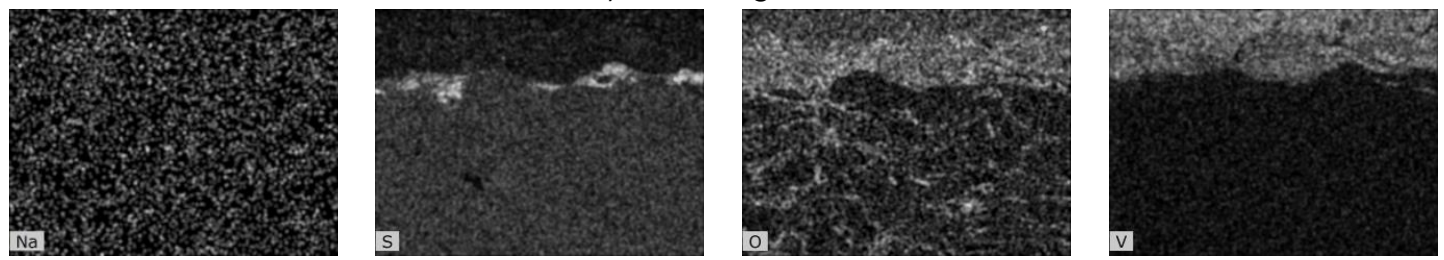

b) Corrosion elements

Figure 5 SEM photograph and EDS map of the cross-section of NiCrMoNbTa coating after the exposure to the $40 \% \mathrm{Na}_{2} \mathrm{SO}_{4}$ a $60 \% \mathrm{~V}_{2} \mathrm{O}_{5}$ corrosion environment a) Elements of the substrate b) Corrosion elements
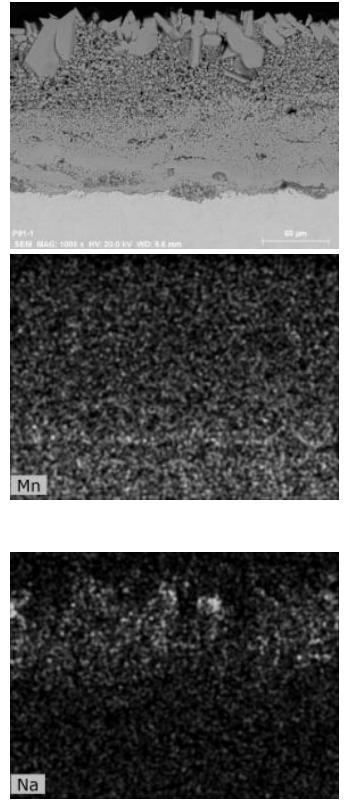

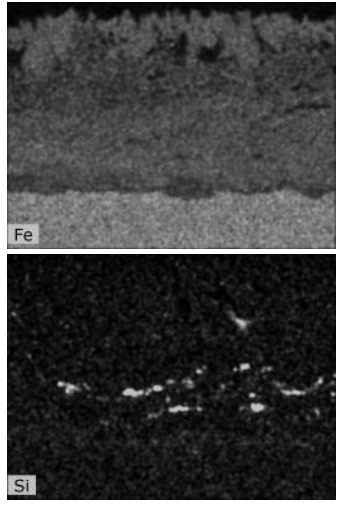

a) Coating elements
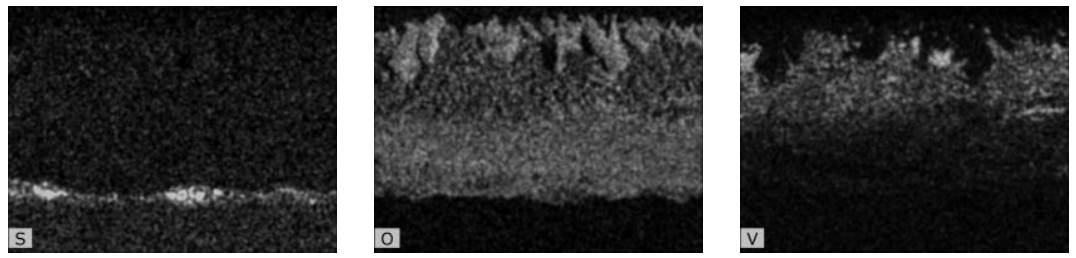

b) Corrosion elements

Figure 6 SEM photograph and EDS map of cross-section of bare steel 1.4903 after the exposure to the $40 \% \mathrm{Na}_{2} \mathrm{SO}_{4}$ a $60 \% \mathrm{~V}_{2} \mathrm{O}_{5}$ corrosion environment a) Elements of the substrate b) Corrosion elements

The bare steel 1.4903 suffered a severe corrosion attack, see (Figure 6). The corrosion layer consists mainly of iron oxides and a smaller amount of oxides of chromium and manganese. The upper half of the corrosion layer is rich in vanadium, which comes from a corrosive environment. The presence of silicon was detected in the corrosion layer, which is probably the residue of the polishing medium used for metallographic preparation. At the interface of the corrosion layers and the base material, a thin area rich in chromium is visible, under which the depleted area is located. Again, molybdenum and sulphur overlapped. 
The SEM micrograph for high temperature corroded steel 1.4959 (Figure 7) reveals the thick corrosion layer formed by oxides of iron, chromium, nickel, manganese, titanium and aluminium. At the interface of the corrosion layer and the base material, a layer rich in sulphur and nickel was formed, this layer is depleted of chromium. The silicon that is found on the surface of the corrosion layer probably comes from a polishing medium. Vanadium diffused into the oxide layers and further into the sample surface. Vanadium and sulphur diffused from the corrosion medium into the corrosion layer.
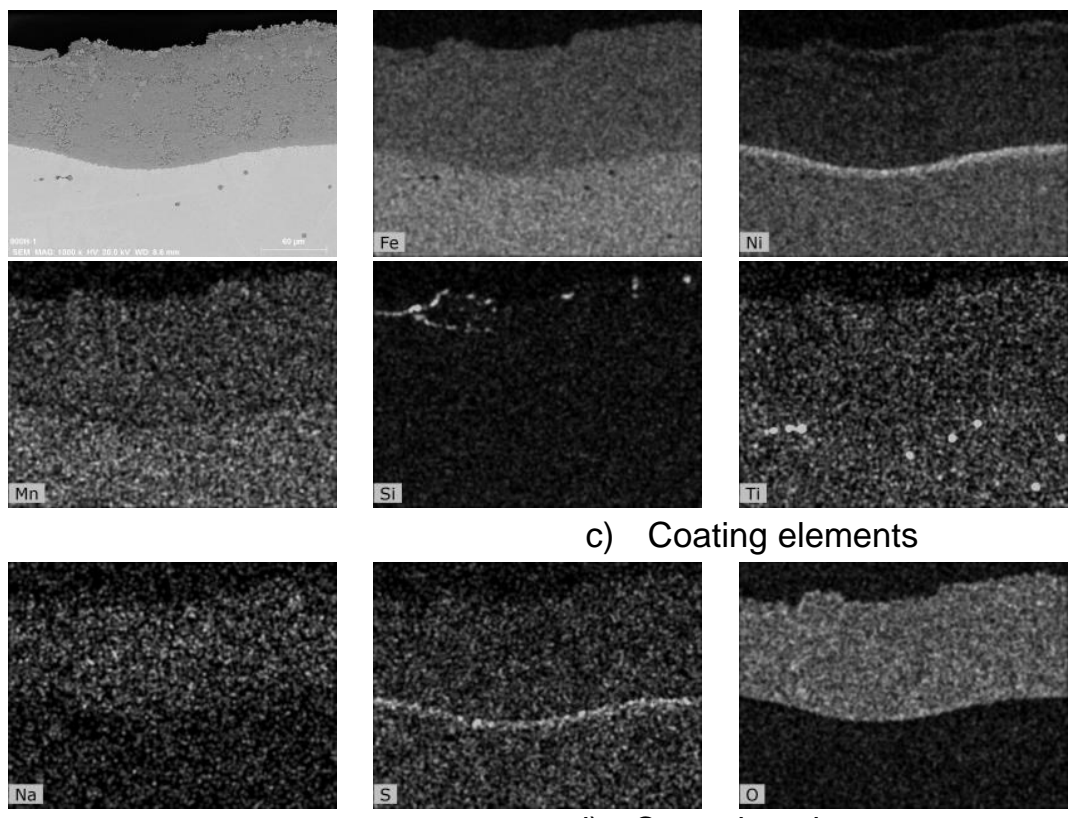

c) Coating elements
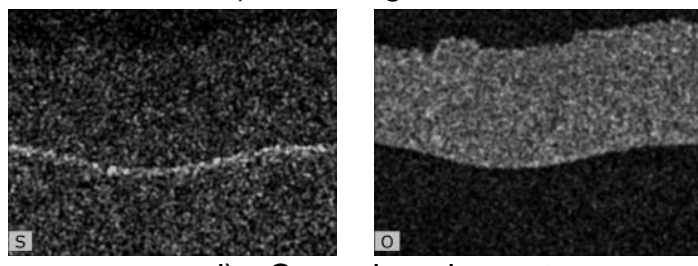

d) Corrosion elements
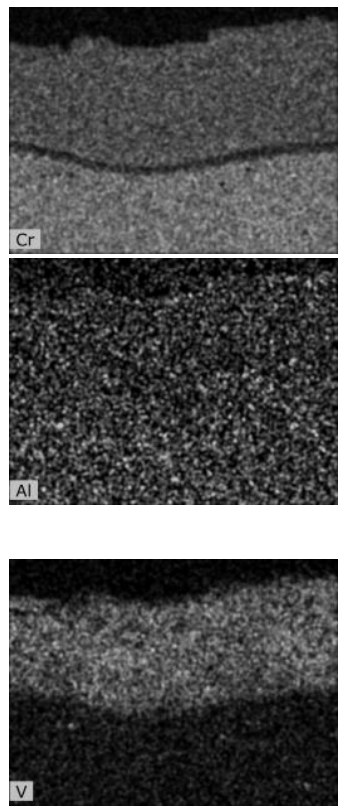

Figure 7 SEM photograph and EDS map of the cross-section of bare steel 1.4959 after the exposure to the $40 \% \mathrm{Na}_{2} \mathrm{SO}_{4}$ a $60 \% \mathrm{~V}_{2} \mathrm{O}_{5}$ corrosion environment a) Elements of the substrate b) Corrosion elements

\subsection{XRD analysis}

Table $1 \mathrm{XRD}$ results for tested samples after exposure to the $40 \% \mathrm{Na}_{2} \mathrm{SO}_{4}$ a $60 \% \mathrm{~V}_{2} \mathrm{O}_{5}$

\begin{tabular}{|c|c|c|}
\hline Sample & Majority phases & Minority phases \\
\hline $\mathrm{NiCr}$ & $\mathrm{Ni}_{3} \mathrm{~V}_{2} \mathrm{O}_{8}, \mathrm{Na}_{2} \mathrm{SO}_{4}$ & - \\
\hline $\mathrm{NiCrMNbTa}$ & $\mathrm{Ni}_{3} \mathrm{~V}_{2} \mathrm{O}_{8}, \mathrm{Na}_{2} \mathrm{SO}_{4}$ & - \\
\hline Bare steel 1.4903 & $\mathrm{Fe}_{2} \mathrm{O}_{3}$ & - \\
\hline Bare steel 1.4959 & $\mathrm{Fe}_{3} \mathrm{O}_{4}, \mathrm{Fe}_{2} \mathrm{O}_{3}$ & - \\
\hline
\end{tabular}

Results of XRD analysis of tested samples after exposure to the molten salt environment $40 \% \mathrm{Na}_{2} \mathrm{SO}_{4}$ a $60 \% \mathrm{~V}_{2} \mathrm{O}_{5}$ are given in (Table 1). The XRD analysis was performed on the surface of the high temperature corrosion tested specimens gently cleaned from the corrosive medium. The XRD analysis of $\mathrm{NiCr}$ and $\mathrm{NiCrMNbTa}$ coatings detect $\mathrm{Ni}_{3} \mathrm{~V}_{2} \mathrm{O}_{8}$ and residues of corrosion environment $\mathrm{Na}_{2} \mathrm{SO}_{4}$ on the top of the corrosion layer. The oxide scale of both uncoated steels is mainly by iron oxides $\mathrm{Fe}_{2} \mathrm{O}_{3}$. In addition, the presence of oxide $\mathrm{Fe}_{3} \mathrm{O}_{4}$ was detected on the top of steel. 1.4959.

\section{CONCLUSION}

In the current investigation, two NiCr-based coatings applied using Twin Wire Arc Spray technology are compared. The $\mathrm{NiCr}$ and $\mathrm{NiCrMNbTa}$ coatings were exposed to the $40 \% \mathrm{Na}_{2} \mathrm{SO}_{4}$ a $60 \% \mathrm{~V}_{2} \mathrm{O}_{5}$ molten salt 
environment at $750^{\circ} \mathrm{C}$ under cyclic condition, simulating the working environment of energy systems burning oil-based fuels.

The coated specimens have shown better hot corrosion behaviour than the bare substrate materials in the present investigation. Both protective coatings showed good corrosion resistance. Based on the thermogravimetric method, it can be said that the NiCrMNbTa coating showed slightly better resistance to high temperature corrosion. The results of EDS and SEM analyses show surface corrosion attack of both coatings. Corrosion layer of coatings is formed dominantly by nickel, chromium and vanadium, which comes from a corrosive environment. Sulphur diffused into the surface of the NiCr coating. Small amounts of nickel, niobium and tantalum were detected in the corrosion layer of NiCrMNbTa coating. In the case of molybdenum and sulphur, the peaks in the EDS spectrum overlap, so they could not be distinguished in the materials containing both elements.

Both bare steel samples suffered severe corrosion attack. On the top of bare steel samples is a thick oxidic layer mainly formed by iron oxides. A small amount of chromium and manganese was detected on the top of the steel 1.4903 corrosion layer. The upper half of the corrosion layer was rich in vanadium from a corrosive environment. At the interface of the corrosion layers and the base material is a thin area rich in chromium. Again, molybdenum and sulphur overlapped. Loss of original shape was observed for the steel 1.4903 sample. The oxide layer of bare steel 1.4959 is formed by iron, chromium, nickel, manganese, titanium, aluminium and vanadium, which comes from a corrosive environment. At the interface of the oxide layer and the base material is a layer rich in sulphur and nickel this layer is depleted of chromium. A small amount of vanadium diffused into the sample surface. Vanadium and sulphur diffused from the corrosion medium into the corrosion layer. The bare steel 1.4959 showed extensive peeling during the entire period of the test.

\section{ACKNOWLEDGEMENTS}

The paper has originated in the framework of institutional support for the long-time conception development of the research institution provided by the Ministry of Industry and Trade of the Czech Republic.

\section{REFERENCES}

[1] SIDHU, T.S, PRAKASH, S, AGRAWAL, R.D. Performance of high-velocity oxyfuel-sprayed coatings on an Febased superalloy in Na2SO4-60\%V2O5 environment at $900{ }^{\circ} \mathrm{C}$ part II: Hot corrosion behavior of the coatings, Tribology International. 2006, vol. 15, pp 130-138.

[2] SIDHU, T.S, MALIK, A, PRAKASH, S ET AL. Oxidation and Hot Corrosion Resistance of HVOF WC-NiCrFeSiB Coating on Ni- and Fe-based Superalloys at $800^{\circ} \mathrm{C}$. Journal of Materials Engineering and Performance. 2007, vol. 16, pp 844-849

[3] SIDHU, T.S, PRAKASH, S. and AGRAWAL, R.D. Hot corrosion and performance of nickel-based coatings, Tribology International. 2006, vol. 90, pp. 41-47

[4] LENCOVÁ, K., ČESÁNEK, Z, HOUDKOVÁ, Š. High temperature corrosion studies of HVOF sprayed coatings in molten sulphate salts environment. In: Proceedings 28th International Conference on Metallurgy and Materials. [online]. Brno: Tanger, 2019, vol 28, pp 1079-1085. Available from: https://doi.org/10.37904/metal.2019.885. 